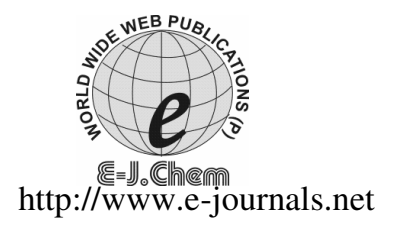

ISSN: 0973-4945; CODEN ECJHAO

E-Journal of Chemistry

2011, 8(2), 615-620

\title{
Synthesis, Characterization and Printing Application of Solvent Dyes Based on 2-Hydroxy-4-n-octyloxybenzophenone
}

\author{
BHARAT C. DIXIT* and HITENDRA M. PATEL \\ Department of Chemistry, V. P. \& R. P. T. P. Science College \\ Vallabh Vidyanagar-388120, Gujarat, India \\ dixits20002003@yahoo.co.in
}

Received 21 September 2010; Accepted 22 November 2010

\begin{abstract}
Solvent dyes have been prepared by the coupling of diazo solution of different aromatic amines with 2-hydroxy-4-n-octyloxybenzophenone. The resultant dyes were characterized by elemental analysis as well as IR and ${ }^{1} \mathrm{H}$ NMR spectral studies. The UV-Visible spectral data have also been discussed in terms of structure property relationship. The printing of all the dyes on cotton fiber was monitored. The result shows that better hue was obtained on printing on cotton fiber and it is resulted in yellow to reddish brown colorations which showed a good fastness to light, with poor to good fastness to washing, perspiration and sublimation, however it shows poor rubbing fastness.
\end{abstract}

Keywords: Solvent dyes, Printing application, Cotton fibre, Light fastness, Washing fastness.

\section{Introduction}

Whilst phenols are well established intermediates for the syntheses of various commercial dyes $^{1-6}$, they are marketed in the form of azo disperse, azo-acid dyes etc. All of these dyes having phenolic moiety, containing hydroxyl group as an auxochrome group. Such auxochromic $(-\mathrm{OH})$ and chromophoric $(\mathrm{C}=\mathrm{O})$ group containing compound i.e. 2-hydroxy-4$n$-octyloxybenzophenone has shown wide applications as a polymer additives ${ }^{7-9}$. It is an excellent UV absorber ${ }^{10}$, which prevents the photo degradability of most of vinyl polymers $^{11-13}$. The area in which the acid azo dyes and mordent azo dyes formation based on this compound has not been developed except of few patents ${ }^{14-17}$.

The formation of solvent dyes based on this compound may yield the dyes with good hue properties. Hence, in continuation of our earlier work ${ }^{18}$, it was thought interesting to explore the field of acid azo dyes based on 2-hydroxy-4-n-octyloxybenzophenone. Thus, the present communication comprises the printing application of solvent dyes based on 2-hydroxy-4-n-octyloxybenzophenone. 


\section{Experimental}

All the chemicals used were of analytical grade and were further purified as and when required. The aromatic amines listed in Scheme 1 were used for diazotization. Cotton fibers were gifted by color tax (Pvt) Ltd, Surat. Melting points were determined by open capillary method and are uncorrected. The visible absorption spectra were measured on a Carl Zeiss UV/VIS Specord spectrometer and elemental analysis was carried out on Perkin Elmer CHNS/O Analyzer 2400 Series II. Infrared spectra were recorded in $\mathrm{KBr}$ pellets on a Perkin-Elmer Spectrum GX FT-IR model, proton NMR spectra were recorded on Hitachi R-1500 in DMSO-D ${ }_{6}$ solvent and TLC (Thin layer chromatography) was run on a aluminum sheets precoated with silica gel $60 \mathrm{~F}_{245}$, (Merck, Germany) using methanol-water-acetic acid (12:3:7) solvent system. Colour spot was visualized by UV chamber. Printing machine (Process controller PC2F/R) was used for printing purpose.

\section{Synthesis of solvent dyes}

\section{Diazotization}

Diazotization of various aromatic amines $\mathbf{1}(\mathbf{a}-\mathbf{g})$ (Scheme 1) was carried out by the method reported in literature ${ }^{19,20}$. Accordingly each of the aromatic amines $\mathbf{1}(\mathbf{a}-\mathbf{g})\left(3.19 \times 10^{-3} \mathrm{~kg}\right.$, $0.01 \mathrm{~mol})$ was mixed with $\mathrm{HCl}\left(2.5 \times 10^{-5} \mathrm{~m}^{3}, 37 \%\right)$ in a mortar, transferred to a 3-neck round bottom flask and additional $\mathrm{HCl}\left(2.0 \times 10^{-5} \mathrm{~m}^{3,} 37 \%\right)$ was added. To the resultant suspension crushed ice $\left(25 \times 10^{-3} \mathrm{~kg}\right)$ and $\mathrm{NaNO}_{2}\left(2.5 \times 10^{-5} \mathrm{~m}^{3}, 4 \mathrm{~N}\right)$ were added. Diazotization was carried out over $0.5 \mathrm{~h}$ at $5^{0} \mathrm{C}$ with constant stirring.

$$
\begin{array}{lll}
\mathrm{Ar}-\mathrm{NH}_{2} & \stackrel{\mathrm{NaNO}_{2}, \mathrm{HCl}}{\mathrm{Ar}} \stackrel{+}{\mathrm{N}}=5^{\circ} \mathrm{C} & \text { Diazonium salts } \\
\text { Aromatic amine } & &
\end{array}
$$

$(\mathrm{a}-\mathrm{j})$
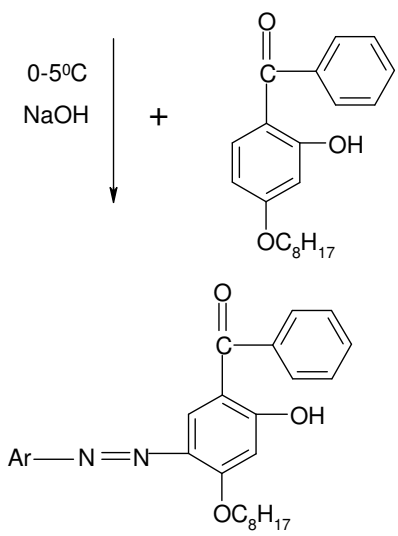

\begin{tabular}{cccccc}
\hline Dyes No & $\mathrm{R}_{1}$ & $\mathrm{R}_{2}$ & $\mathrm{R}_{3}$ & $\mathrm{R}_{4}$ & Dyes $\left(\mathbf{D}_{1}-\mathbf{D}_{7}\right)$ \\
\hline $\mathrm{D}_{1}$ & $\mathrm{NO}_{2}$ & $\mathrm{H}$ & $\mathrm{H}$ & $\mathrm{H}$ & 2- Nitroaniline \\
$\mathrm{D}_{2}$ & $\mathrm{H}$ & $\mathrm{H}$ & $\mathrm{NO}_{2}$ & $\mathrm{H}$ & 4- Nitroaniline \\
$\mathrm{D}_{3}$ & $\mathrm{H}$ & $\mathrm{NO}_{2}$ & $\mathrm{H}$ & $\mathrm{H}$ & 3-Nitroaniline \\
$\mathrm{D}_{4}$ & $\mathrm{Cl}$ & $\mathrm{H}$ & $\mathrm{NO}_{2}$ & $\mathrm{Cl}$ & 2,6 - Dichloro-4-nitroaniline \\
$\mathrm{D}_{5}$ & $\mathrm{CH}_{3}$ & $\mathrm{H}$ & $\mathrm{CH}_{3}$ & $\mathrm{H}$ & 2,4-Dimethylaniline \\
$\mathrm{D}_{6}$ & $\mathrm{H}$ & $\mathrm{Cl}$ & $\mathrm{H}$ & $\mathrm{H}$ & 3-Chloroaniline \\
$\mathrm{D}_{7}$ & $\mathrm{H}$ & $\mathrm{H}$ & $\mathrm{Cl}$ & $\mathrm{H}$ & 4-Chloroaniline \\
\hline
\end{tabular}

Scheme 1. Proposed synthetic rout for the preparation of solvent dyes 


\section{Coupling procedure}

The coupling of above mentioned diazotized aromatic amines $\mathbf{1}(\mathbf{a}-\mathbf{g})$ was carried out in the similar manner. The general procedure followed is given below: 2-Hydroxy-4- $n$ octyloxybenzophenone $\left(2.15 \times 10^{-3} \mathrm{~kg}, 0.01 \mathrm{~mol}\right)$ was dissolved in sodium hydroxide $\left(1.2 \times 10^{-5} \mathrm{~m}^{3}, 0.01 \mathrm{~mol}\right)$ solution. The clear solution was cooled in ice-bath and diazonium solution of aromatic amines 1(a-g) was added drop wise over a period of $30 \mathrm{~min}$ with vigorous stirring. The $\mathrm{pH}$ was maintained between 2.0 to 3.0 by simultaneous addition of $10 \%$ w/v sodium carbonate solution. Stirring was continued for $2 \mathrm{~h}$, allowing the temperature to rise to ambient. The dyes was then filtered off and dissolved in distilled water after that solvent dyes were obtained by evaporation procedure and it was dried at room temperature. The dyes were designated as solvent dye $\left(\mathrm{D}_{1-7}\right)$ and were recrystalised in acetone.

Printing on cotton fiber

Solvent dyes $\left(\mathrm{D}_{1}-\mathrm{D}_{7}\right)$ used for printing of cotton fiber was carried out by the method reported in literature ${ }^{21}$.

\section{Characteristic data of solvent dyes}

1-[2-Hydroxy-4-n-octyloxy -5-(2-nitrophenylazo)phenyl]-1-phenylmethanone $\left(D_{1}\right)$

Calculated for $\mathrm{C}_{27} \mathrm{H}_{29} \mathrm{O}_{5} \mathrm{~N}_{3}$ : M. wt.: 475 , \% yield: 88, m. p.: $47-49{ }^{0} \mathrm{C}, \mathrm{R}_{\mathrm{f}}$ value: $0.82 ; \mathrm{C}$, $68.21 \%$; H, 6.10\%; N, 8.84\%. Found: C, 68.19\%; H, 5.98\%; N, 8.81\%. IR: $3463 \mathrm{~cm}^{-1}$ $(-\mathrm{OH}) ; 3072 \mathrm{~cm}^{-1}\left(=\mathrm{CH}\right.$, aromatic); $1628 \mathrm{~cm}^{-1}(\mathrm{C}=\mathrm{O}$, diaryl $) ; 1521 \mathrm{~cm}^{-1}(\mathrm{~N}=\mathrm{N}) ; 1481 \mathrm{~cm}^{-1}$ $\left(\mathrm{C}=\mathrm{C}\right.$, aromatic); $1333 \mathrm{~cm}^{-1}(\mathrm{C}-\mathrm{N}) ; 1101 \mathrm{~cm}^{-1}$ (C-O); 1212-1024 $\mathrm{cm}^{-1}$ (C-O-C, stretching); $732 \mathrm{~cm}^{-1}, 584 \mathrm{~cm}^{-1}, 481 \mathrm{~cm}^{-1}$ (for substituted benzene). ${ }^{1} \mathrm{H}$ NMR: $10.7 \delta$ (Ar-OH, singlet), 7.2-7.4 $\delta$ (Ar-H, multiplet), $3.6 \delta$ (-OC $\mathrm{OH}_{17}$, singlet, $\left.3 \mathrm{H}\right), 2.8 \delta\left(-\mathrm{CH}_{2^{-}}\right.$, multiplet), $2.23 \delta$ $\left(-\mathrm{CH}_{3}\right.$, singlet, $\left.3 \mathrm{H}\right), 1.8 \delta$ and $1.2 \delta$ (triplet, $-\mathrm{CH}_{3}$ and $-\mathrm{CH}_{2}-$ ).

\section{1-[2-Hydroxy-4-n-octyloxy -5-(4-nitrophenylazo)phenyl]-1-phenylmethanone $\left(\mathrm{D}_{2}\right)$}

Calculated for $\mathrm{C}_{27} \mathrm{H}_{29} \mathrm{O}_{5} \mathrm{~N}_{3}$ : M. wt.: 475 , \% yield: 92 , m. p.: $52-54{ }^{0} \mathrm{C}, \mathrm{R}_{\mathrm{f}}$ value: $0.80 ; \mathrm{C}$, $68.21 \%$; H, 6.10\%; N, 8.84\%. Found: C, 68.17\%; H, 5.94\%; N, 8.78\%. IR: $3450 \mathrm{~cm}^{-1}$ $(-\mathrm{OH}) ; 3082 \mathrm{~cm}^{-1}\left(=\mathrm{CH}\right.$, aromatic); $1624 \mathrm{~cm}^{-1}(\mathrm{C}=\mathrm{O}$, diaryl $) ; 1522 \mathrm{~cm}^{-1}(\mathrm{~N}=\mathrm{N}) ; 1490 \mathrm{~cm}^{-1}$ $\left(\mathrm{C}=\mathrm{C}\right.$, aromatic); $1345 \mathrm{~cm}^{-1}(\mathrm{C}-\mathrm{N}) ; 1101 \mathrm{~cm}^{-1}$ (C-O); $1032 \mathrm{~cm}^{-1}, 1211-1021 \mathrm{~cm}^{-1}$ (C-O-C, stretching); $744 \mathrm{~cm}^{-1}, 564 \mathrm{~cm}^{-1}, 478 \mathrm{~cm}^{-1}$ (for substituted benzene). ${ }^{1} \mathrm{H}$ NMR: $10.6 \delta$ (Ar-OH, singlet), 7.1-7.3 $\delta$ (Ar-H, multiplet), $3.8 \delta\left(-\mathrm{OC}_{8} \mathrm{H}_{17}\right.$, singlet, $\left.3 \mathrm{H}\right), 2.4 \delta\left(-\mathrm{CH}_{2-}\right.$, multiplet), $2.13 \delta\left(-\mathrm{CH}_{3}\right.$, singlet, $\left.3 \mathrm{H}\right), 1.6 \delta$ and $1.4 \delta$ (triplet, $-\mathrm{CH}_{3}$ and $-\mathrm{CH}_{2}-$ ).

\section{1-[2-Hydroxy-4-n-octyloxy -5-(3-nitrophenylazo)phenyl]-1-phenylmethanone $\left(\mathrm{D}_{3}\right)$}

Calculated for $\mathrm{C}_{27} \mathrm{H}_{29} \mathrm{O}_{5} \mathrm{~N}_{3}$ : M. wt.: 475 , \% yield: 87, m. p.: $50-53{ }^{0} \mathrm{C}, \mathrm{R}_{\mathrm{f}}$ value: $0.85 ; \mathrm{C}$, $68.21 \%$; H, 6.10\%; N, 8.84\%. Found: C, 68.15\%; H, 5.96\%; N, 8.76\%. IR : $3481 \mathrm{~cm}^{-1}$ $(-\mathrm{OH}) ; 3070 \mathrm{~cm}^{-1}\left(=\mathrm{CH}\right.$, aromatic); $1632 \mathrm{~cm}^{-1}(\mathrm{C}=\mathrm{O}$, diaryl $) ; 1542 \mathrm{~cm}^{-1}(\mathrm{~N}=\mathrm{N}) ; 1483 \mathrm{~cm}^{-1}$ $\left(\mathrm{C}=\mathrm{C}\right.$, aromatic); $1337 \mathrm{~cm}^{-1}(\mathrm{C}-\mathrm{N}) ; 1103 \mathrm{~cm}^{-1}$ (C-O); 1212-1020 $\mathrm{cm}^{-1}$ (C-O-C, stretching); $1029 \mathrm{~cm}^{-1}, 737 \mathrm{~cm}^{-1}, 562 \mathrm{~cm}^{-1}, 472 \mathrm{~cm}^{-1}$ (for substituted benzene). ${ }^{1} \mathrm{H}$ NMR: $10.9 \delta$ (Ar-OH, singlet), 7.1-7.3 (Ar-H, multiplet), $3.7 \delta\left(-\mathrm{OC}_{8} \mathrm{H}_{17}\right.$, singlet, $\left.3 \mathrm{H}\right), 2.6 \delta$ (- $\mathrm{CH}_{2^{-}}$, multiplet), $2.27 \delta\left(-\mathrm{CH}_{3}\right.$, singlet, $\left.3 \mathrm{H}\right), 1.4 \delta$ and $1.1 \delta$ (triplet, $-\mathrm{CH}_{3}$ and $-\mathrm{CH}_{2}-$ ).

\section{1-[2-Hydroxy-4-n-octyloxy-5-(2,5-dichloro-4-nitrophenylazo)phenyl]-1-} phenylmethanone $\left(D_{4}\right)$

Calculated for $\mathrm{C}_{27} \mathrm{H}_{27} \mathrm{O}_{5} \mathrm{~N}_{3} \mathrm{Cl}_{2}$ : M. wt.: $544, \%$ yield: 78 , m. p.: $66-69{ }^{0} \mathrm{C}, \mathrm{R}_{\mathrm{f}}$ value: $0.87 ; \mathrm{C}$, $59.55 \%$; H, $4.96 \%$; N, 7.72\%. Found: C, 59.49\%; H, 4.92\%; N, 7.68\%. IR : $3633 \mathrm{~cm}^{-1}$ $(-\mathrm{OH}) ; 3080 \mathrm{~cm}^{-1}\left(=\mathrm{CH}\right.$, aromatic); $1652 \mathrm{~cm}^{-1}\left(\mathrm{C}=\mathrm{O}\right.$, diaryl); $1532 \mathrm{~cm}^{-1}(\mathrm{~N}=\mathrm{N}) ; 1473 \mathrm{~cm}^{-1}$ 
$\left(\mathrm{C}=\mathrm{C}\right.$, aromatic); $1338 \mathrm{~cm}^{-1}(\mathrm{C}-\mathrm{N}) ; 1104 \mathrm{~cm}^{-1}$ (C-O); 1210-1021 $\mathrm{cm}^{-1}$ (C-O-C, stretching); $1032 \mathrm{~cm}^{-1}, 782 \mathrm{~cm}^{-1}, 741 \mathrm{~cm}^{-1}, 583 \mathrm{~cm}^{-1}, 485 \mathrm{~cm}^{-1}$ (for substituted benzene). ${ }^{1} \mathrm{H}$ NMR: 10.6 $\delta$ (Ar-OH, singlet), 7.3-7.7 $\delta$ (Ar-H, multiplet), $3.5 \delta\left(-\mathrm{OC}_{8} \mathrm{H}_{17}\right.$, singlet, $\left.3 \mathrm{H}\right), 2.4 \delta\left(-\mathrm{CH}_{2}-\right.$ ,multiplet), $2.24 \delta\left(-\mathrm{CH}_{3}\right.$, singlet, $\left.3 \mathrm{H}\right), 1.6 \delta$ and $1.4 \delta$ (triplet, $-\mathrm{CH}_{3}$ and $-\mathrm{CH}_{2}-$ ).

\section{1-[2-Hydroxy-4-n-octyloxy-5-(2,4-dimethylphenylazo)phenyl]-1-} phenylmethanone $\left(D_{5}\right)$

Calculated for $\mathrm{C}_{29} \mathrm{H}_{34} \mathrm{O}_{3} \mathrm{~N}_{2}$ : M. wt.: 458 , \% yield: 82, m. p.: $45-47{ }^{0} \mathrm{C}, \mathrm{R}_{\mathrm{f}}$ value: $0.86 ; \mathrm{C}$, $75.98 \%$; H, 7.42\%; N, 6.11\%. Found: C, 75.94\%; H, 7.39\%; N, 6.08\%. IR : $3580 \mathrm{~cm}^{-1}$ (-OH, phenolic); $3070 \mathrm{~cm}^{-1}$ (=CH, aromatic); $1621 \mathrm{~cm}^{-1}\left(\mathrm{C}=\mathrm{O}\right.$, diaryl); $1531 \mathrm{~cm}^{-1}(\mathrm{~N}=\mathrm{N})$; $1482 \mathrm{~cm}^{-1}\left(\mathrm{C}=\mathrm{C}\right.$, aromatic); $1463 \mathrm{~cm}^{-1}(\mathrm{C}-\mathrm{N}) ; 1338 \mathrm{~cm}^{-1}(\mathrm{C}-\mathrm{O}) ; 1210-1023 \mathrm{~cm}^{-1}$ (C-O-C, stretching), $1034 \mathrm{~cm}^{-1}, 1103 \mathrm{~cm}^{-1}, 732 \mathrm{~cm}^{-1}, 574 \mathrm{~cm}^{-1}, 473 \mathrm{~cm}^{-1}$ (for substituted benzene). ${ }^{1} \mathrm{H}-\mathrm{NMR}$ : $10.6 \delta$ (Ar-OH, singlet), 7.2-7.6 $\delta$ (Ar-H, multiplet), $3.4 \delta\left(-\mathrm{OC}_{8} \mathrm{H}_{17}\right.$, singlet, $\left.3 \mathrm{H}\right)$, $2.5 \delta$ (- $\mathrm{CH}_{2-}$, multiplet), $2.21 \delta\left(-\mathrm{CH}_{3}\right.$, singlet, $\left.3 \mathrm{H}\right), 1.6 \delta$ and $1.3 \delta$ (triplet, $-\mathrm{CH}_{3}$ and $-\mathrm{CH}_{2}-$ ).

\section{1-[2-Hydroxy-4-n-octyloxy -5-(3-chlorophenylazo)phenyl]-1-phenylmethanone $\left(D_{6}\right)$}

Calculated for $\mathrm{C}_{27} \mathrm{H}_{29} \mathrm{O}_{3} \mathrm{~N}_{2} \mathrm{Cl}$ : M. wt.: 464 , \% yield: 76 , m. p.: $55-58{ }^{0} \mathrm{C}, \mathrm{R}_{\mathrm{f}}$ value: 0.83 ; $\mathrm{C}$, $69.82 \%$; H, 6.25\%; N, 6.03\%. Found: C, 69.78\%; H, 6.21\%; N, 5.97\%. IR : $3430 \mathrm{~cm}^{-1}(-\mathrm{OH}$, phenolic); $3540 \mathrm{~cm}^{-1}$ (-OH, acidic); $3062 \mathrm{~cm}^{-1}$ (=CH, aromatic); $1634 \mathrm{~cm}^{-1}(\mathrm{C}=\mathrm{O}$, diaryl); 1581 $\mathrm{cm}^{-1}(\mathrm{~N}=\mathrm{N}) ; 1483 \mathrm{~cm}^{-1}\left(\mathrm{C}=\mathrm{C}\right.$, aromatic); $1352 \mathrm{~cm}^{-1}(\mathrm{C}-\mathrm{N}) ; 1103 \mathrm{~cm}^{-1}(\mathrm{C}-\mathrm{O}) ; 1210-1022 \mathrm{~cm}^{-1}$ (C-O-C, stretching); $783 \mathrm{~cm}^{-1}, 741 \mathrm{~cm}^{-1}, 583 \mathrm{~cm}^{-1}, 482 \mathrm{~cm}^{-1}$ (for substituted benzene). ${ }^{1} \mathrm{H}$ NMR: $10.8 \delta$ (Ar-OH, singlet), 7.3-7.5 $\delta$ (Ar-H, multiplet), $3.7 \delta\left(-\mathrm{OC}_{8} \mathrm{H}_{17}\right.$, singlet, $\left.3 \mathrm{H}\right)$, $2.5 \delta$ (- $\mathrm{CH}_{2^{-}}$,multiplet), $2.27 \delta\left(-\mathrm{CH}_{3}\right.$, singlet, $\left.3 \mathrm{H}\right), 1.9 \delta$ and $1.3 \delta$ (triplet, $-\mathrm{CH}_{3}$ and $-\mathrm{CH}_{2}-$ ).

1-[2-Hydroxy-4-n-octyloxy-5-(4-chlorophenylazo)phenyl]-1-phenylmethanone $\left(D_{7}\right)$

Calculated for $\mathrm{C}_{28} \mathrm{H}_{32} \mathrm{O}_{3} \mathrm{~N}_{2}$ : M. wt.: 444 , \% yield: 85 , m. p.: $43-46{ }^{0} \mathrm{C}, \mathrm{R}_{\mathrm{f}}$ value: $0.85 ; \mathrm{C}$, $75.67 \%$; H, $7.20 \%$; , $6.30 \%$. Found: C, $75.62 \%$ H, $7.17 \%$; N, $6.27 \%$. IR : $3590 \mathrm{~cm}^{-1}$ $(-\mathrm{OH}) ; 3063 \mathrm{~cm}^{-1}\left(=\mathrm{CH}\right.$, aromatic); $1632 \mathrm{~cm}^{-1}(\mathrm{C}=\mathrm{O}$, diaryl $) ; 1533 \mathrm{~cm}^{-1}(\mathrm{~N}=\mathrm{N}) ; 1471 \mathrm{~cm}^{-1}$ $\left(\mathrm{C}=\mathrm{C}\right.$, aromatic); $1324 \mathrm{~cm}^{-1}(\mathrm{C}-\mathrm{N}) ; 1103 \mathrm{~cm}^{-1}$ (C-O); 1211-1023 $\mathrm{cm}^{-1}$ (C-O-C, stretching);1031 $\mathrm{cm}^{-1}, 780 \mathrm{~cm}^{-1}, 744 \mathrm{~cm}^{-1}, 586 \mathrm{~cm}^{-1}, 475 \mathrm{~cm}^{-1}$ (for substituted benzene). ${ }^{1} \mathrm{H}$ NMR: $10.6 \delta$ (Ar-OH, singlet), 7.1-7.6 $\delta$ (Ar-H, multiplet), $3.8 \delta\left(-\mathrm{OC}_{8} \mathrm{H}_{17}\right.$, singlet, $\left.3 \mathrm{H}\right)$, $2.6 \delta$ ( $-\mathrm{CH}_{2^{-}}$, multiplet), $2.24 \delta\left(-\mathrm{CH}_{3}\right.$, singlet, $\left.3 \mathrm{H}\right), 1.7 \delta$ and $1.4 \delta$ (triplet, $-\mathrm{CH}_{3}$ and $-\mathrm{CH}_{2}-$ ).

\section{Fastness property}

The fastness to light, sublimation and perspiration of dye pattern was assessed according to British standard: 1006-1978 and the wash fastness test according to Indian standard: IS: 765-1979. The rubbing fastness was tested by using Crock meter (Atlas) AATCC-1961, shown in Table 2.

\section{Determination of the percentage exhaustion and fixation}

The dye bath percentage exhaustion and fixation of the dyed fabric was determined according to the known method ${ }^{22}$ and is shown in Table 1.

\section{Results and Discussion}

Physical properties of solvent dyes

All the dyes are obtained as crystal powder ranging from yellow to reddish brown in colours. The purity of the dyes were checked by TLC using methanol-water-acetic acid (12:3:7) solvent system. The TLC results show that only single spot observed for each dye. The purified dyes have melting point measured by open capillary tube. The melting points were uncorrected. 
The results of elemental analysis content of each dyes are consistent with the predicted structure as shown in Scheme 1. The number of azo group is almost one for each dye. The nitrogen content and number of azo group for each dye are co-related with each other. The IR spectrum of each dye comprises the important features of aromatic, azo, hydroxyl, alkoxy and keto groups. The ${ }^{1} \mathrm{H}$ NMR spectra of all the diazo compounds based on 2-hydroxy-4- $n$ octyloxybenzophenone shows an important signals at their respective positions confirmed the structures of various dyes as shown in Scheme 1.

The visible absorption spectroscopic properties of dyes were recorded in double distilled water. The absorption maxima $\left(\lambda_{\max }\right)$ of all the dyes fall into the range of $346-410 \mathrm{~nm}$ in water, as shown in Table 1 . The value of the logarithm of molar extinction coefficient $(\log \varepsilon)$ of all the dyes were in the range of $4.11-4.28$, consistent with their high intensity of absorption.

Table 1. Absorption maxima $\left(\lambda_{\max }\right)$, intensities $(\log \varepsilon)$, exhaustion $(E)$ and fixation $(F)$ of solvent dyes on cotton

\begin{tabular}{ccccc}
\hline Dyes & Absorption maxima & Intensities & \multicolumn{2}{c}{ Printing on Cotton } \\
\cline { 4 - 5 } No. & $\lambda_{\max } /$ nm In DMF & $\log \varepsilon$ & $\% \mathrm{E}$ & $\% \mathrm{~F}$ \\
\hline $\mathrm{D}_{1}$ & 346 & 4.216 & 80 & 89 \\
$\mathrm{D}_{2}$ & 352 & 4.193 & 75 & 94 \\
$\mathrm{D}_{3}$ & 385 & 4.167 & 72 & 90 \\
$\mathrm{D}_{4}$ & 349 & 4.280 & 85 & 89 \\
$\mathrm{D}_{5}$ & 385 & 4.117 & 74 & 86 \\
$\mathrm{D}_{6}$ & 410 & 4.172 & 71 & 88 \\
$\mathrm{D}_{7}$ & 397 & 4.185 & 85 & 92 \\
\hline
\end{tabular}

Moreover, the presence of electron donating or electron attracting groups did not bring about any marked increase or decreased in $\lambda_{\max }$ in the visible region and that $\log \varepsilon$ remained nearly constant. However, electron attracting substituents like $-\mathrm{NO}_{2}$ and $-\mathrm{Cl}$ in the substituent group of the coupler increase polarizability, and will results in bathochromic shifts. This leads to decrease in energy between the highest occupied molecular orbital and lowest unoccupied molecular orbital and thus $\pi \rightarrow \pi^{*}$ electronic transition takes place at lower frequency photon, resulting in the bathochromic shift of the visible absorption band.

\section{Dyeing properties of dyes}

The solvent dyes were applied at $2 \%$ depth on cotton fabric respectively. Their printing properties are given in Table 2. These dyes gave a wide range of colours varying from yellow to reddish brown shades with good levelness, brightness and depth on the fabrics.

Table 2. Results of solvent dyes on printing and various fastness properties of dyes on cotton

\begin{tabular}{|c|c|c|c|c|c|c|c|c|}
\hline \multirow{2}{*}{$\begin{array}{c}\text { Dyes } \\
\text { No. }\end{array}$} & \multirow{2}{*}{$\begin{array}{l}\text { Color shades on } \\
\text { cotton }\end{array}$} & \multirow{2}{*}{$\begin{array}{c}\text { Light } \\
\text { fastness }\end{array}$} & \multirow{2}{*}{$\begin{array}{l}\text { Washing } \\
\text { fastness }\end{array}$} & \multicolumn{2}{|c|}{$\begin{array}{l}\text { Perspiration } \\
\text { fastness }\end{array}$} & \multirow{2}{*}{$\begin{array}{l}\text { Sublimation } \\
-\quad \text { fastness }\end{array}$} & \multicolumn{2}{|c|}{$\begin{array}{l}\text { Rubbing } \\
\text { fastness }\end{array}$} \\
\hline & & & & Acid & Alkaline & & Dry & Wet \\
\hline $\mathrm{D}_{1}$ & Orange brown & 5 & 5 & 4 & 5 & 4 & 4 & 4 \\
\hline $\mathrm{D}_{2}$ & Reddish brown & 5 & 4 & 4 & 4 & 4 & 4 & 4 \\
\hline$D_{3}$ & Reddish orange & 5 & 5 & 5 & 5 & 5 & 4 & 4 \\
\hline $\mathrm{D}_{4}$ & Light yellow & 4 & 5 & 4 & 5 & 4 & 4 & 3 \\
\hline $\mathrm{D}_{5}$ & Chocolate brown & 4 & 4 & 5 & 5 & 4 & 4 & 4 \\
\hline $\mathrm{D}_{6}$ & Yellow & 5 & 5 & 5 & 5 & 5 & 4 & 3 \\
\hline $\mathrm{D}_{7}$ & Yellow & 5 & 4 & 5 & 5 & 4 & 4 & 4 \\
\hline
\end{tabular}


The variation in the shades of the dye fabric results from both the nature and position of the substituent present on the diazotized compound. The dyeing showed an excellent fastness to light, with very good to excellent fastness to washing, perspiration and sublimation, however it shows poor rubbing fastness. A remarkable degree of levelness after washing is observed. This may be attributed to good penetration and affinity of the dye molecule in to fiber structure.

\section{Conclusion}

Produced solvent dyes have good fastness to light but show poor sublimation and rubbing fastness properties. The nature of the substituent in the coupling components has a little influence on the visible absorption and shade of the printing. All the solvent dyes show a good solubility in various organic solvents therefore, they may be useful as fuel dye and in printing ink.

\section{Acknowledgment}

The authors are thankful to the principal, for providing necessary research facilities. Authors are also thankful to Mr. Ashok C. Kapadia, Mr. Pradeep N. Mistry of Color Tax (Pvt) Ltd., Surat for characterization of azo group and giving the standard of fastness properties and Raju Mehta of G.P.C.B., Surat for providing useful chemicals.

\section{References}

1. Cumming W M and Howie G, J Chem Soc., 1933, 133-135.

2. Peters A T and Walker D, J Chem Soc., 1956, 429.

3. Vogel A I, A Textbook of Practical Organic Chemistry, $3^{\text {rd }}$ Ed., Longman: London, 1961, 620.

4. Gordon P F and Gregory P, Organic Chemistry in Colour, $1^{\text {st }}$ Ed., Springer-Verlag Berlin Heidelberg: New York, 1983, 60.

5. Mohamed S K and Nour El-Din A M, J Chem Res., (S) 1999, 8, 508-509.

6. Naik R D, Desai C K and Desai K R, Oriental J Chem., 2000, 16, 159.

7. Yurteri S, Onen and Yagci Y, Eur Polym J., 2002, 38(9), 1845-1850.

8. Huang W and Hou B, Tribology Letters Springer US, 2004, 18(4), 445.

9. Huang, Lu X, Springer Berlin Heidelberg, New York, 2005, 56(2), 171.

10. Vink P and and Van Veen Th J, Eur Polym J., 1978, 14(7), 533.

11. Johnson M and Hauserman R G, J Appl Poly Sci., 1977, 21, 3457-3463.

12. Kamogawa H and Nanasawa M, Yukio Uehara, 1977, 15, 675-677.

13. Allmer K, Hult A and Ranby B, J Poly Sci., 1989, 27, 3419-3427.

14. Frantisek V and Hana N, Czech., 1979, 176, 377. (CA 91:P58685x).

15. Raouf B, American Colour \& Chemical Corp US pat., 4, 1978, 066, 388, (CA 88:P106751c)

16. Brian B and Donald C, Sandoz- pat. G.M.B.H. DE 3, 1984, 417, 782. (CA 102: P133487k)

17. Rohr T M and Kuhn J (Ciba-Geigy A-G) Eur Pat Appl EP 169, 808 (Cl. G03C5/52) 29 Jan 1986 CH Appl 84/ 3, 577; 24 Jul 1984 CA. 104 : P 216418 f.

18. Dixit B C, Patel H M and Desai D J, J Serb Chem Soc., 2007, 72, 119.

19. Frirz-David H E and Blengy L, Fandamental Process of Dye Chemistry, $3^{\text {rd }}$ Ed., Willy: New York, 1949, 241.

20. Szymczyk M, Shafei AE and Freeman H S, Dyes and Pigments, 2007, 72, 8.

21 Mehmef K and Peter J H, Textile Res J., 2004, 74(1), 43-50.

22. Shishtawy R M E, Youssef Y A, Ahmed N S E and Mousa A A, Dyes and Pigments 2007, 72(1), 57. 


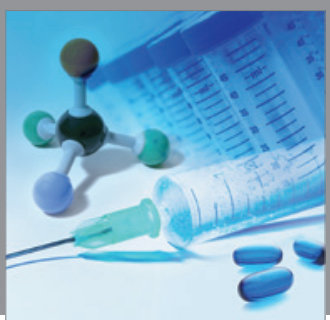

International Journal of

Medicinal Chemistry

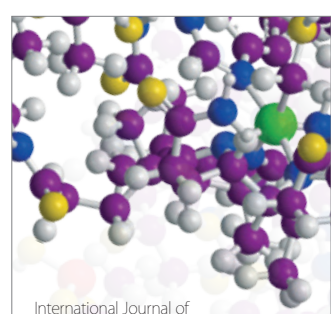

Carbohydrate Chemistry

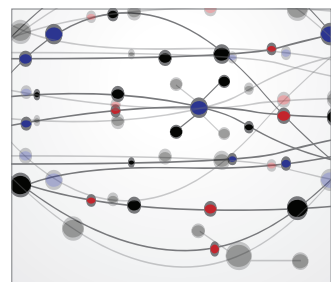

The Scientific World Journal
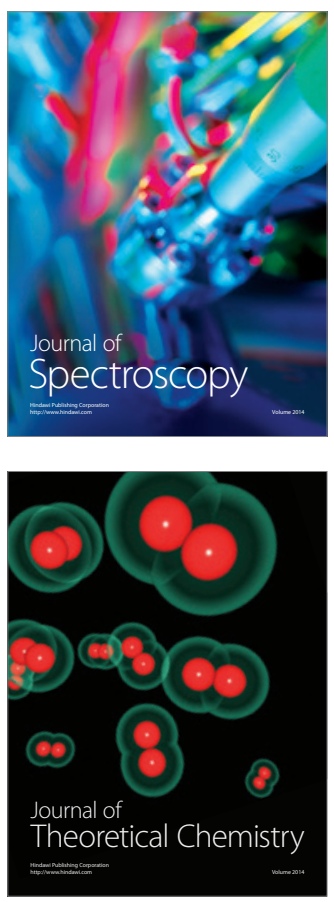
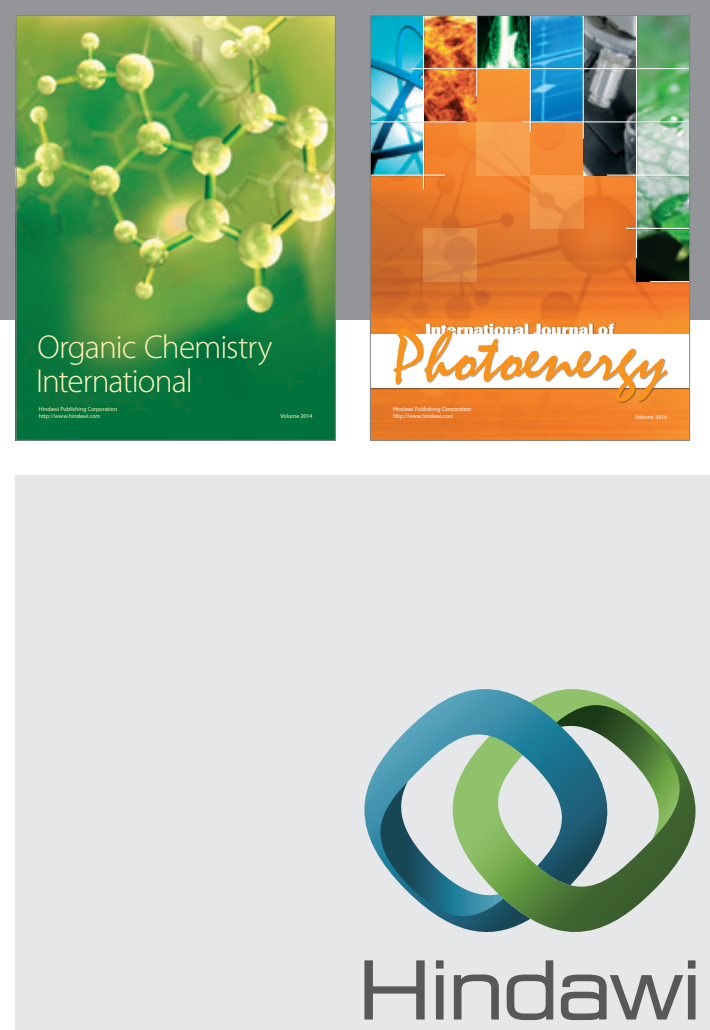

Submit your manuscripts at

http://www.hindawi.com
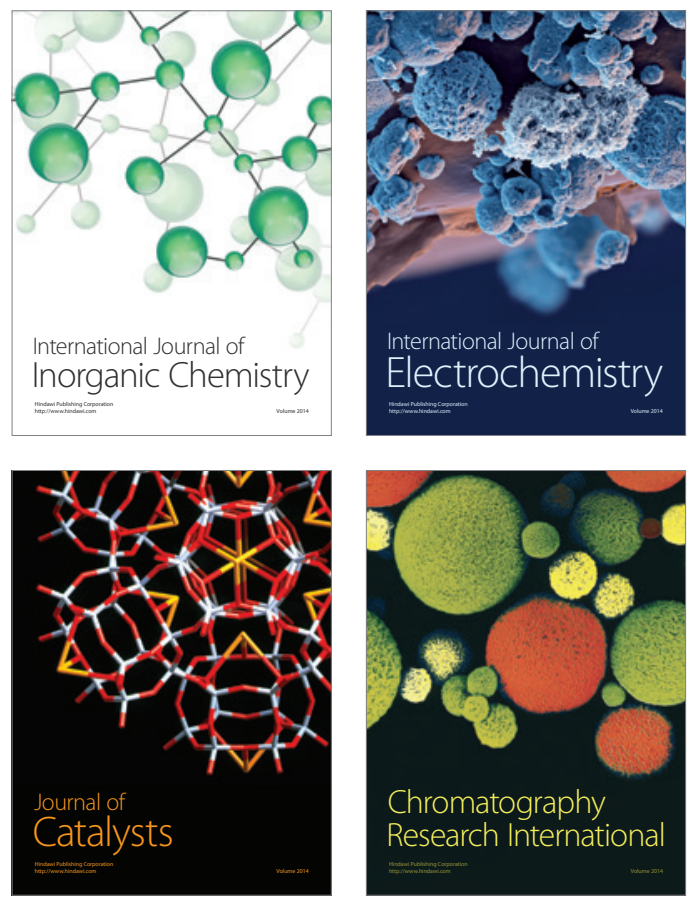
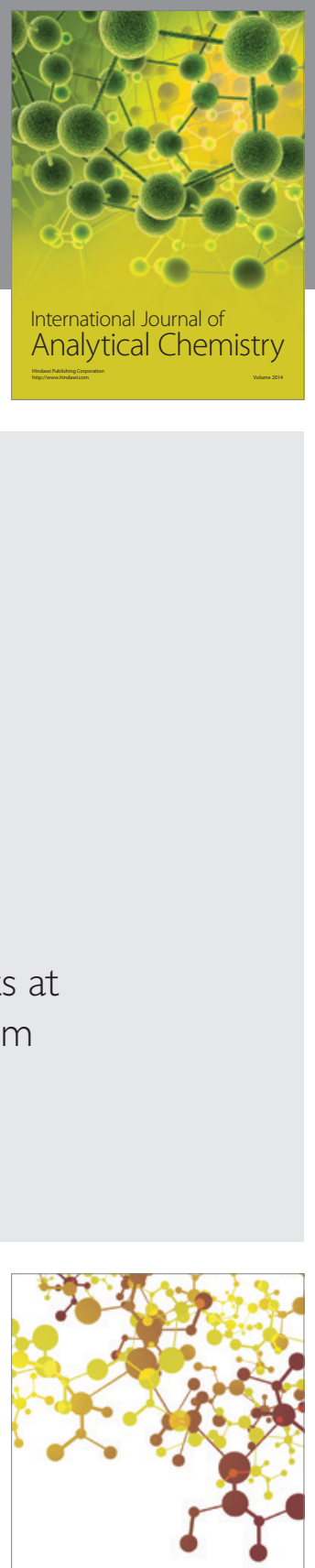

Journal of

Applied Chemistry
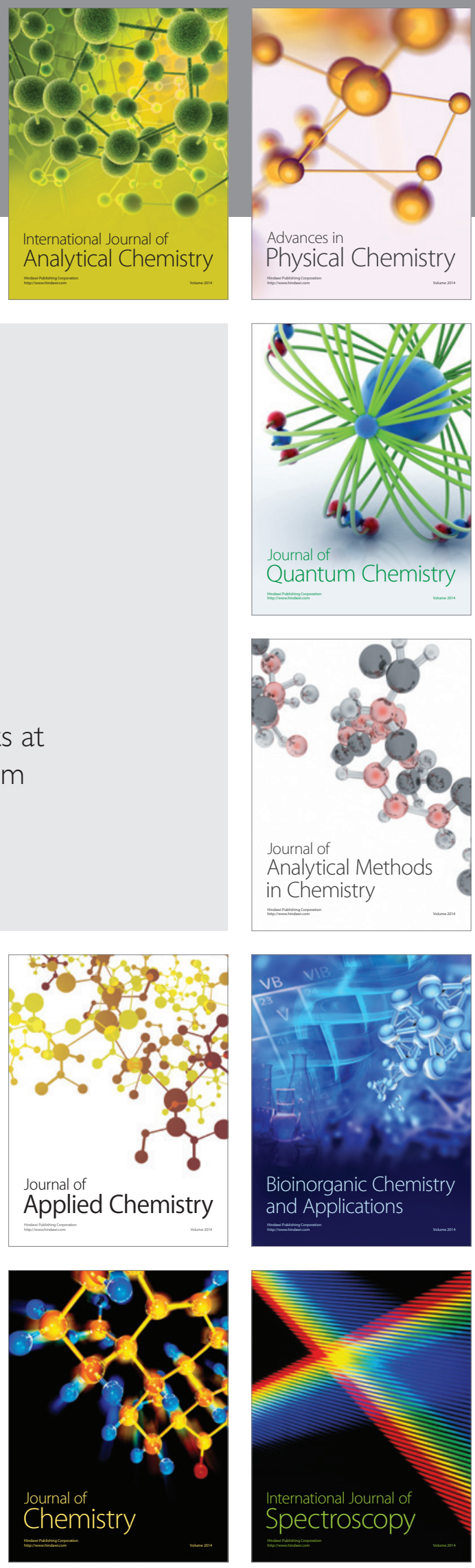